\title{
Temporal RNA Integrity Analysis of Archived Spaceflight Biological Samples
}

\author{
Elizabeth Delgadillo Talburt ${ }^{1}$, Alison J. French ${ }^{2}$, Danielle K. Lopez ${ }^{2}$, San-Huei Lai Polo ${ }^{2}$, Valery Boyko ${ }^{2}$, \\ Marie T. Dinh ${ }^{2}$, Jon C. Rask ${ }^{2}$, Helen J. Stewart ${ }^{3}$, and Kaushik Chakravarty ${ }^{4}$ \\ ${ }^{1}$ Volunteer Internship Program, National Aeronautics and Space Administration (NASA) Ames Research Center, \\ Moffett Field, California; ${ }^{2}$ Wyle Labs, Inc., Moffett Field, California; ${ }^{3}$ National Aeronautics and Space \\ Administration (NASA) Ames Research Center, Moffett Field, California; ${ }^{4}$ Logyx LLC, Mountain View, California
}

\begin{abstract}
In spaceflight experiments, model organisms are used to assess the effects of microgravity on specific biological systems. In many cases, only one biological system is of interest to the Principal Investigator. To maximize the scientific return of experiments, the remaining spaceflight tissue is categorized, documented, and stored in the biobank at NASA Ames Research Center, which is maintained by the Ames Life Science Data Archive (ALSDA). The purpose of this study is to evaluate the state of a sample set of tissues from the ALSDA biobank. Garnering information such as downstream functional analysis for the generation of omics datasets - from tissues is, in part, dependent on the state of sample preservation. RNA integrity number (RIN) values have been calculated for rodent liver tissues that were part of scientific payloads returned from the International Space Station (ISS). Rat livers from
\end{abstract}

Key words: $\quad$ RNA Integrity Number;

Spaceflight Tissues; Biobanking

Correspondence to: Kaushik Chakravarty

ARC Life Sciences Data Archive and

Biobank

NASA Ames Research Center

Moffett Field, CA 94035

Telephone: 216-577-8124

E-mail: kchak1@gmail.com
Spacelab Life Sciences 1 (SLS-1) and mouse livers from Commercial Biomedical Test Module 3 (CBTM-3), Rodent Research 1 (RR1), and Rodent Research 3 (RR3) were tested. It was found that mean RIN values from CBTM-3, RR1, and RR3 were suitable for downstream functional analysis (RIN > 5) while the mean RIN value for SLS-1 was not $(\mathrm{RIN}=2.5 \pm 0.1)$. Information from this study lays the foundation for future efforts in determining the types of assays that are most appropriate for different tissues in the ALSDA biobank and similar preservation facilities, which would aid in shaping the design of experiments.

\section{INTRODUCTION}

Tissues in the ALSDA biobank originate from scientific payloads that have been returned from the International Space Station. These payloads provide invaluable insight on the changes in biological systems in the spaceflight environment. The ability to obtain maximal information from these tissues is essential, given their rarity and the high cost associated with sending organisms to the ISS.

The ALSDA biobank holds thousands of spaceflight biospecimens that vary in tissue type, organ, and animal model. The dissection procedures, fixatives, age, and specimen containers are other examples of storage variation. For this study, RNA was extracted from rodent 
livers that have been continuously stored in $-80^{\circ} \mathrm{C}$ freezers after the date of collection. There were no organs from a single species that spanned across time. However, this study focused on the ability to garner information from tissues regardless of the species, and elucidates the effect of time and storage.

To quantify tissue integrity, RIN values were calculated. RNA integrity is an indicator of the ability to obtain gene expression data (Fleige and Pfaffl, 2006) and downstream functional analysis, such as quantitative real-time PCR, micro-arrays, northern blot, in situ hybridization, and RNA mapping among other assays (Imbeaud et al., 2005; Fleige and Pfaffl, 2006; Fleige et al., 2006; Koppelkamm et al., 2011). Historically, the ratio between 28S and 18S ribosomal RNA (rRNA) as determined through electropherogram images was used to determine RNA quality (Shroeder et al., 2006). However, this method was relatively inconsistent due to the subjectivity of human interpretation of electropherogram images. To overcome inconsistencies in determining RNA integrity, the RNA integrity number algorithm was developed (Imbeaud et al., 2006).

\section{MATERIALS AND METHODS}

\section{Biospecimens}

Livers from Sprague Dawley adult rats and C57BL/6J mice from the NASA Ames Research Center ALSDA biobank were examined in this study. Table 1 describes the origins of these tissues and lists pertinent information that may have had an effect on the RNA quality, such as the dissection protocol or fixative (liquid nitrogen $\left(\mathrm{LN}_{2}\right)$ or RNAlater) used for storage. As a positive control, fresh livers from C57BL/6J mice were used. Sample weights ranged from $11.4 \mathrm{mg}$ to $28.2 \mathrm{mg}$; tissues from RR1 were not weighed but were of the same relative size as all other tissues included.

\section{RNA Extraction}

RNA extractions for liver samples from SLS1 and RNAlater-preserved RR3 liver samples were performed by the ALSDA. NASA's GeneLab had previously performed RNA extractions on CBTM-3, RR1, and RR3 livers preserved in $\mathrm{LN}_{2}$ for an unrelated study. Their data was provided to this study. All RNA extractions, done by the ALSDA and GeneLab, were performed in accordance with the QIAGEN DNA/RNA AllPrep Mini Handbook. Liquid nitrogen fixed livers were cut on dry ice and weighed quickly before being placed in sample vials containing pre-chilled nuclei lysis buffer from the AllPrep kits. Using chilled lysis buffer is standard practice in GeneLab RNA extractions from frozen samples as it had been found in an inhouse protocol optimization study to yield the highest concentration of RNA. For consistency, chilled lysis buffer was used on all RNA extractions, including the positive control.

Cryovials with samples fixed in RNAlater were thawed on ice to free the liver specimens from the frozen RNAlater before being cut and weighed. The weights of each liver sample processed in this study ranged from 20-26 mg. After weighing, liver samples were placed in a nuclei lysis buffer and homogenized with a handheld homogenizer. Each lysate was pipetted into a DNA spin column for initial filtration and washing. The flow through from each DNA spin column was then filtered through an RNA spin column and washed with AllPrep buffers. RNA was eluted using RNase free water.

\section{RNA Integrity Number (RIN) Value Determination}

All RIN values, calculated by the ALSDA and GeneLab, were determined using the Agilent Bioanalyzer 2100 system; SLS-1, CBTM-3, and RR3 samples were run using RNA nano kits and preparation protocol. RR1 samples were run using RNA pico kits and preparation protocol. RNA nano chips and RNA pico chips held twelve and eleven samples, respectively. Each chip was loaded with a gel-dye mix, with a sample or reference ladder, and RNA marker. RNA concentrations of all extracts were within the quantitative range for analysis: 25 to $500 \mathrm{ng} / \mu \mathrm{l}$. Chips were analyzed using the Agilent Bioanalyzer software. RIN values were calculated by the Agilent software, which used electropherogram results to perform the algorithm. RIN values for SLS-1 and RR3 RNAlaterpreserved liver samples were determined by the ALSDA. All other data was provided courtesy of GeneLab, which followed the same described protocol. 
Table 1. Tissues and protocols used in experimental study.

\begin{tabular}{|c|c|c|c|c|c|c|}
\hline Year & $\begin{array}{l}\text { Experimental } \\
\text { Groups }\end{array}$ & Payload & $\begin{array}{l}\text { Animal } \\
\text { Model }\end{array}$ & $\begin{array}{l}\text { Storage } \\
\text { Container }\end{array}$ & Fixative & Dissection Protocol \\
\hline 1991 & Ground $(\mathrm{N}=4)$ & SLS-1 & Rat & Foil & $\mathrm{LN}_{2}$ & $\begin{array}{l}\text { Rats were dissected upon shuttle return. } \\
\text { Rats were sacrificed by decapitation, then } \\
\text { dissected immediately. Livers were } \\
\text { removed, placed on tinfoil, and frozen on } \\
\text { dry ice immediately. }\end{array}$ \\
\hline 2011 & $\begin{array}{c}\text { Ground }(\mathrm{N}=3) \\
\text { Flight }(\mathrm{N}=3) \\
\text { Basal }(\mathrm{N}=3)\end{array}$ & СВТМ-3 & Mouse & Cryovial & $\mathrm{LN}_{2}$ & $\begin{array}{l}\text { Mice were sacrificed by } 4 \% \text { isoflurane } \\
\text { inhalation and dissected within } 3-5.5 \text { hours } \\
\text { after shuttle landing and snap-frozen in } \\
\text { liquid nitrogen. }\end{array}$ \\
\hline 2014 & $\begin{array}{c}\text { Ground }(\mathrm{N}=5) \\
\text { Flight }(\mathrm{N}=5)\end{array}$ & RR1 & Mouse & Cryovial & $\mathrm{LN}_{2}$ & $\begin{array}{l}\text { Mice were sacrificed on board the ISS, } \\
\text { then frozen at }-80^{\circ} \mathrm{C} \text {. Mouse carcasses } \\
\text { were taken from }-80^{\circ} \mathrm{C} \text { freezer and thawed } \\
\text { at room temperature for approximately } 20 \\
\text { minutes. Livers were taken and either } \\
\text { snap-frozen in } \mathrm{LN}_{2} \text { or placed into cryovials } \\
\text { with RNAlater. }\end{array}$ \\
\hline 2016 & $\begin{array}{c}\text { Ground }(\mathrm{N}=6) \\
\text { Flight }(\mathrm{N}=6)\end{array}$ & RR3 & Mouse & Cryovial & $\mathrm{LN}_{2}$ & $\begin{array}{l}\text { Mice were sacrificed on board the ISS, } \\
\text { then frozen at }-80^{\circ} \mathrm{C} \text {. Mouse carcasses } \\
\text { were taken from }-80^{\circ} \mathrm{C} \text { freezer and thawed } \\
\text { at room temperature for approximately } 20 \\
\text { minutes. Livers were taken and either } \\
\text { snap-frozen in } \mathrm{LN}_{2} \text { or placed into cryovials } \\
\text { with RNAlater. }\end{array}$ \\
\hline 2016 & $\begin{array}{c}\text { Ground }(\mathrm{N}=4) \\
\text { Flight }(\mathrm{N}=4)\end{array}$ & RR3 & Mouse & Cryovial & RNAlater & $\begin{array}{l}\text { Mice were sacrificed on board the ISS, } \\
\text { then frozen at }-80^{\circ} \mathrm{C} \text {. Mouse carcasses } \\
\text { were taken from }-80^{\circ} \mathrm{C} \text { freezer and thawed } \\
\text { at room temperature for approximately } 20 \\
\text { minutes. Livers were taken and either } \\
\text { snap-frozen in } \mathrm{LN}_{2} \text { or placed into cryovials } \\
\text { with RNAlater. }\end{array}$ \\
\hline
\end{tabular}

\section{Statistical Analysis}

All statistical analyses were performed using Prism 6.07 software analysis tools (GraphPad Software, Incorporated). Data were divided by payload for a total of five groups, which included a positive control. One-way analysis of variance (ANOVA) was used to determine if there were a significant difference in mean RIN values between one or more groups within a 99\% confidence interval. Since the payload groups had different sample sizes, Tukey's Multiple Comparison Test was used to determine significance between groups within a 99\% confidence interval. To compare mean RIN values of the liquid nitrogen and RNAlater fixed tissues from RR3, a two-tailed, unpaired t-test with Welch's correction was conducted since the two fixative groups had unequal sample sizes; significance was determined within a 95\% confidence interval.

\section{RESULTS}

\section{RIN Values by Payload}

Mean RIN values for each payload were calculated. RIN values for each treatment group - 
ground, flight, and basal level expressions of genes of interest, when available - were combined to calculate a payload mean. Figure 1 shows these values plotted against time. SLS-1, the oldest payload, had the lowest mean RIN value. The highest mean RIN value was from CBTM-3. Mean RIN values from CBTM-3, RR1, and RR3 were all above 7.

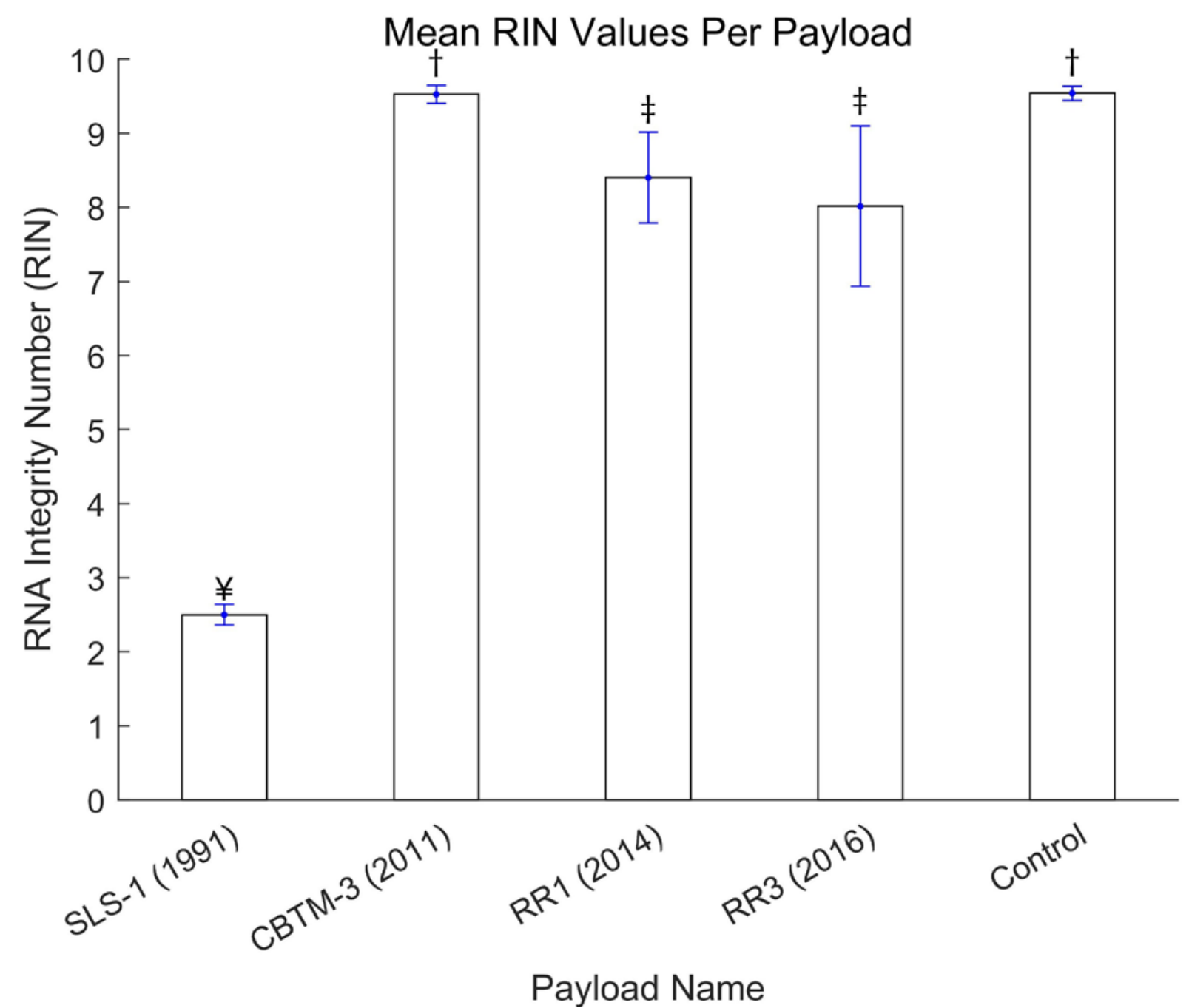

Figure 1. Quantitative temporal comparison of RNA integrity number (RIN) values of rodent liver tissue samples from scientific payloads returned from the International Space Station from 1991 to 2016. Error bars represent standard error of the mean. Significance within a $99 \%$ confidence interval was determined using Tukey's Multiple Comparisons Test. Significant difference from all $(p<0.01)$; significance from Spacelab Life Sciences 1 (SLS-1), Rodent Research 1 (RR1), and Rodent Research 3 (RR3) $(p<0.01)$; and significance from SLS-1, Commercial Biomedical Test Module $3(\mathrm{CBTM}-3)$, and the control $(p<0.01)$ is indicated by the symbols $¥, \dagger$, and $\ddagger$, respectively. The sample sizes for SLS-1, CBTM-3, RR1, RR3, and control tissues are $n=4, n=9, n=10, n=20$, and $n=12$, respectively.

RIN values in Figure 1 were calculated as a quantitative measurement of RNA degradation. As a qualitative analysis, Agilent Bioanalyzer generated gel electrophoresis results were examined. Figure 2 depicts these electropherograms. Each lane is representative of 
its respective payload. RNA degradation is visualized through the number and location of each band. SLS-1 had the most degraded RNA. RNA from CBTM-3 appears the least degraded.
However, CBTM-3, RR1, and RR3 all had gel lanes that depict minimally degraded RNA when compared to the positive control lane.

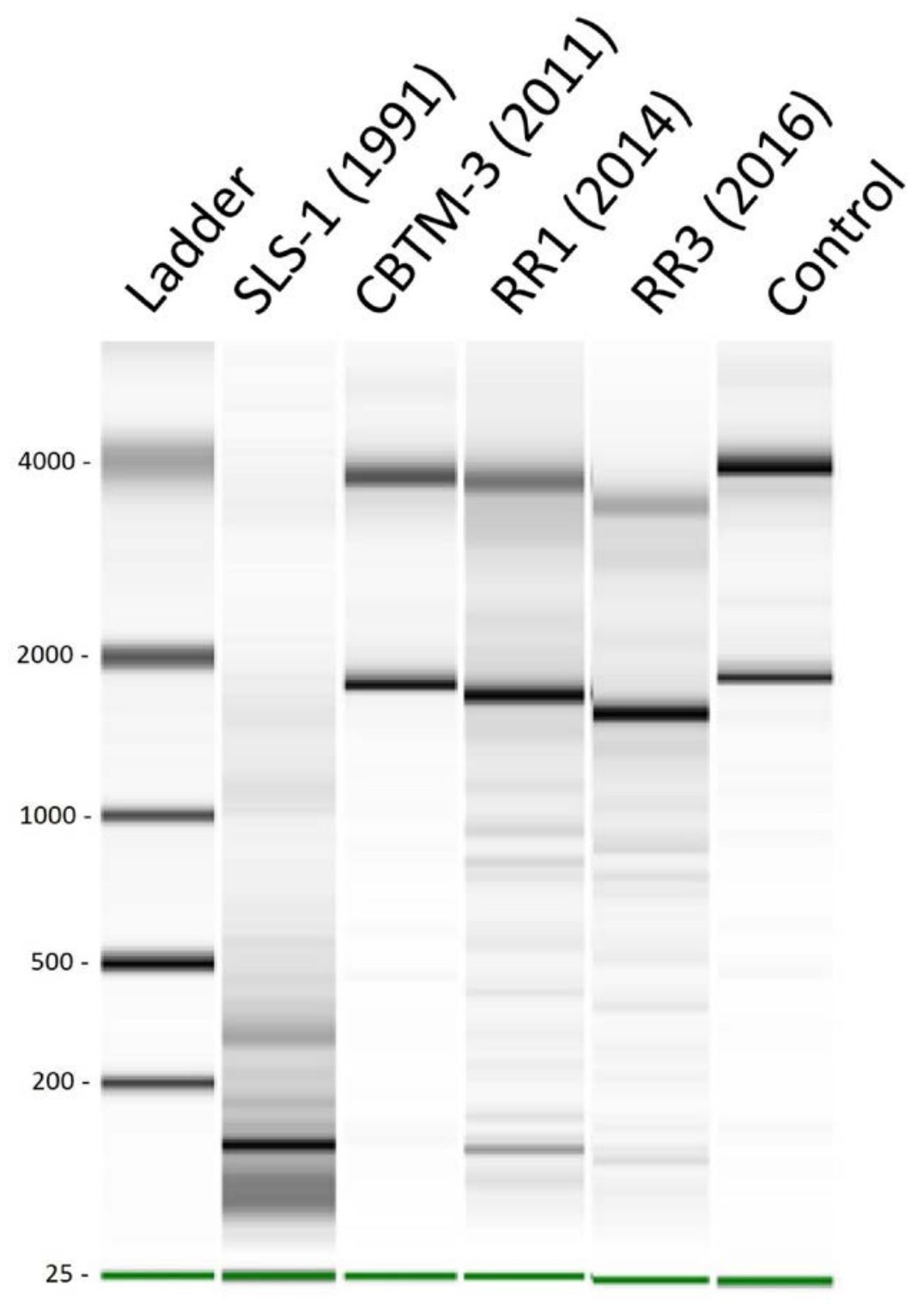

Figure 2. Qualitative temporal comparison of RNA depicting the overall quality of each extraction protocol generated using the Agilent Bioanalyzer 2100 System. Extractions were derived from the Spacelab Life Sciences 1 (SLS-1), Commercial Biomedical Test Module 3 (CBTM-3, Rodent Research 1 (RR1), and Rodent Research 3 (RR3) and control tissue.

\section{RIN Values by Treatment Group}

RIN values were calculated for each treatment group within each payload. Treatment groups consisted of flight, ground, and basal level expressions of genes of interest. SLS-1 had no flight samples available. Figure 3 shows the comparison of RIN values between payloads by treatment group. Error bars represent the standard error of the mean. There was no significant 
difference between treatment group RIN values within a payload, which was concluded as all mean RIN values compared were within the standard error of the mean.

\section{RIN Values by Fixative}

Comparisons were drawn between sample preservation conditions. The tissues from RR3 were fixed in either liquid nitrogen $\left(\mathrm{LN}_{2}\right)$ or RNAlater. For both cases, the liver tissues were stored in cryovials after fixation and kept at $-80^{\circ} \mathrm{C}$. In Figure 4, these two conditions are compared; mean RIN values were determined for each fixative condition. Error bars represent the standard error of the mean. RNAlater preserved livers had a higher mean RIN value after one year in $-80^{\circ} \mathrm{C}$ storage. However, both values are suitable for downstream functional analyses (RIN $>5$ ).

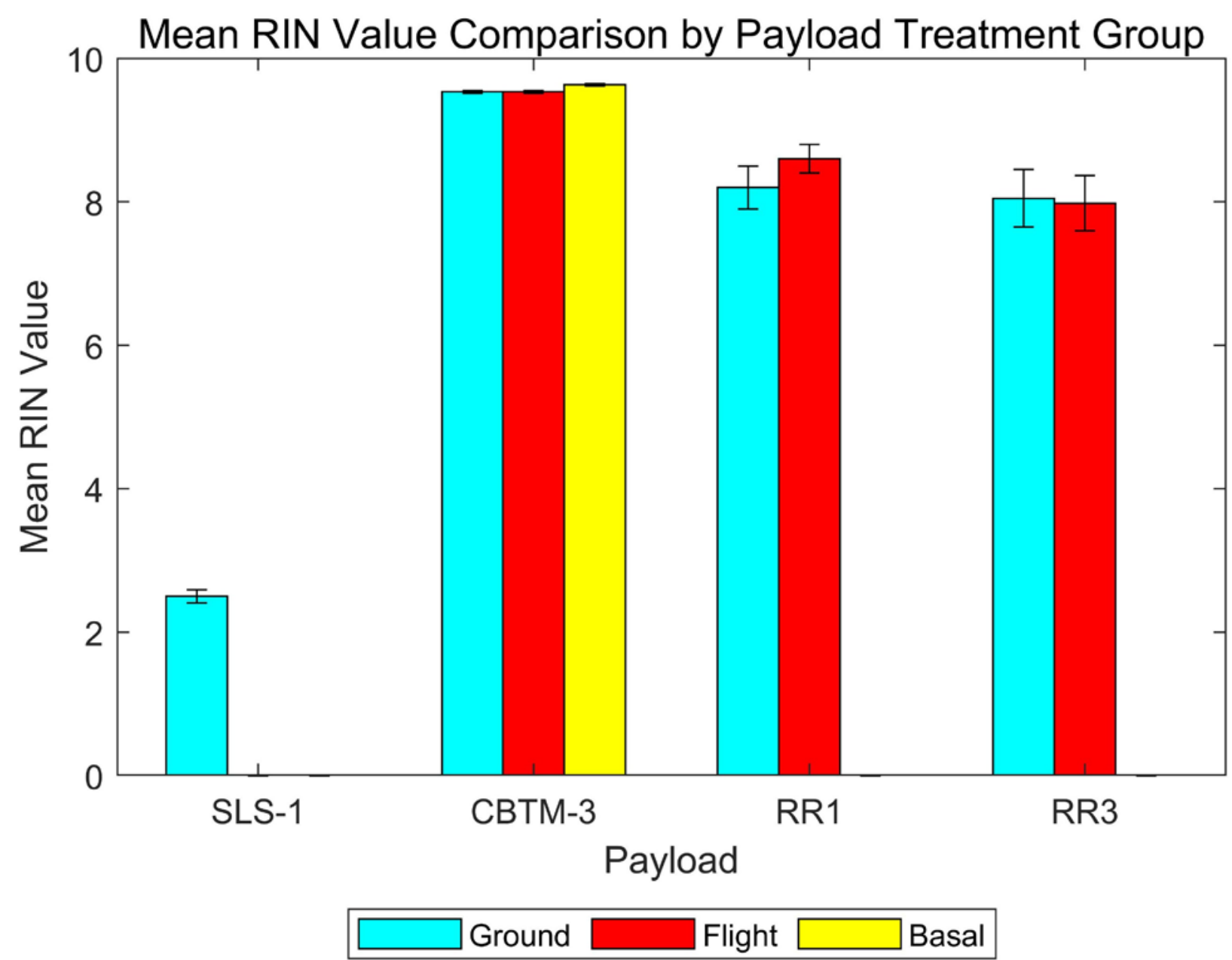

Figure 3. RIN comparison between payloads by treatment group. Payloads divided into subgroups by treatment type - ground, flight, and basal - when applicable. There was no significant difference between treatment groups within any payload. In each subgroup, the payloads SLS-1, CBTM-3, RR1, and RR3 had sample sizes of $n=4, n=3, n=5$, and $n=10$, respectively. 


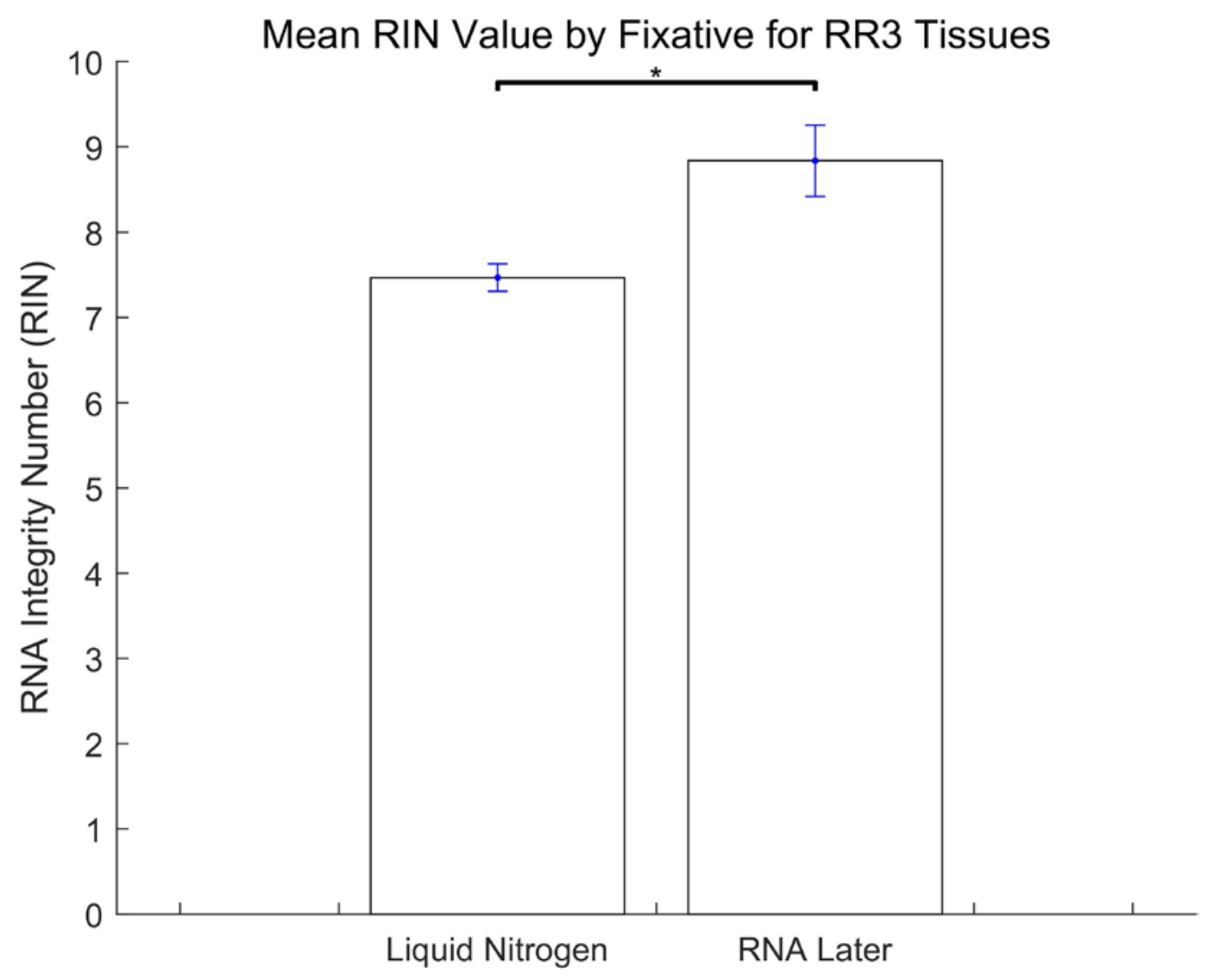

Figure 4. Mean RIN values of RR3 livers compared between fixative methods. Error bars represent SEM and the asterisk indicates a significant difference $(p<0.05$, two-tailed t-test with Welch's Correction). For the liquid nitrogen fixed group and the RNAlater fixed group, the sample sizes were $n=12$ and $n=8$, respectively.

\section{DISCUSSION}

\section{Duration of Storage and Storage Methods May Affect RIN Values}

Livers from payload SLS-1 (1991) had the lowest mean RIN value, as shown in Figure 1. This could be the result of several factors, which are discussed in Table 1 . Tissues from this payload were stored in tin foil and frozen on dry ice immediately after rodents were sacrificed. The tin foil may not have been free of RNases or may not have protected the tissues sufficiently from contamination while in storage. The dissection protocol did not specify if the tin foil had been cleaned with an RNase decontaminating solution. Additionally, given that these tissues were the oldest samples and tested after being in storage for twenty-six years, the age and duration of storage may have affected the RIN values. Since there are several variables that could have contributed to RNA degradation, a primary cause cannot be stated definitively.

Payloads CBTM-3, RR1, and RR3 all had mean RIN values that were within a workable range for downstream functional analysis such as RNA-seq expression analysis, transcript analysis, or variant identification (Zeng and Mortazavi, 2012). The initial dates of storage for CBTM-3, RR1, and RR3 tissues are 2011, 2014, and 2016, respectively. Although there is a five year difference in storage from CBTM-3 to RR3, the mean RIN values do not differ greatly. Since there are several variables that could have contributed to these RIN values, a primary cause cannot be stated definitively. All liver tissues from these three payloads were stored in cryovials, which may have contributed to their increased RIN values when compared with SLS-1 tissues. 
CBTM-3 and RR1 tissues were fixed in $\mathrm{LN}_{2}$. RR3 tissues were fixed in either $\mathrm{LN}_{2}$ or RNAlater.

\section{Tissue Fixatives Appear to Influence RIN}

Since RR3 tissues were fixed in either $\mathrm{LN}_{2}$ or RNAlater after undergoing the same dissection protocol, the effect of fixatives could be examined. Figure 4 suggests that fixatives seem to have had an effect on RIN values. After reviewing the dissection protocols of these tissues, the only variation appears to be in their fixative; therefore, the difference in RIN can be attributed to the fixative used. After one year in $-80^{\circ} \mathrm{C}$ storage, RNAlater fixed liver tissues had a higher mean RIN value than those that were snap frozen. Our analysis revealed the difference was statistically different $(p=0.0269,95 \%$ confidence interval).

\section{Treatment Group Did Not Affect RIN}

The treatment group - flight, ground, or basal - did not affect RIN values, as shown in Figure 3. This could be because, despite being from different treatment groups, rats and mice from an individual payload underwent the same dissection protocol and were stored for the same period of time. In this case, the treatment group did not affect the ability to garner information from tissues, although the treatment group may affect the information itself.

\section{Significance}

The significance of this study is to provide temporal insight into the integrity of tissues held in $-80^{\circ} \mathrm{C}$ storage. RIN values provide a quantitative indicator of the degree of degradation of RNA. Intact RNA is needed for RNA-seq (Wang et al., 2016), real-time PCR (Schroeder et al., 2006; Fleige et al., 2006), DNA microarray and reverse transcriptase PCR (Salazar et al., 2013), and northern blot analysis (Fleige and Pfaffl, 2006; Koppelkamm et al., 2011) among other tests. Measuring gene expression can be done via real-time PCR; therefore, the integrity of RNA can have an impact on the ability to determine gene expression profiles. Degraded RNA can also affect microRNA analyses (Ibberson et al., 2009).

Although RNA integrity is essential for many assays, degraded RNA has been used for qPCR (Imbeaud et al. 2005). Tissue samples with low RIN values had relative gene expression profiles that were comparable. If RIN values were low among all samples, the gene expression profiles were valid (Gallego Romero et al., 2014; Imbeaud et al., 2005). When RIN values among samples varied, the results declined in quality (Imbeaud et al., 2005). Gene expression profiles can be built if the RIN values are noted and taken into consideration (Imbeaud et al. 2005; Sigurgeirsson et al., 2014). Gene expression data and downstream functional analyses are especially popular with spaceflight tissue samples because of the large amounts of data that can be generated from relatively small tissue samples. Gathering genomics and other omics data sets can be used for data mining to compare complex biological conditions and pathways (Lee et al., 2008).

Although RIN values are not an allencompassing analysis of tissue integrity, the method is especially useful for tissues that are unique or of limited quantity, much like the tissues used in this study (Fleige and Pfaffl, 2006). With larger sets of tissue samples, histological staining could also be used to assess tissue integrity. However, histological staining methods can significantly affect the integrity of RNA (Wang et al., 2006). With compromised RNA, the genomic and downstream functional analysis methods listed previously would be difficult or impossible to conduct.

RIN values were shown to differ between biospecimens held in ALSDA freezers. These difference in RIN values could be attributed to the age, storage method, and fixative used on these tissues. Additional work should be done to expand this study to other organ types and animal models. Assessing the RIN value provided a glimpse into the current state of the biospecimens stored by the ALSDA. This knowledge is a foundation for future studies that can aid Principal Investigators in their assay and biospecimen selection.

\section{Additional Work}

Other organs should be evaluated to assess the difference in RIN values between tissue types. Including additional biological systems and model organisms will build a more robust guide for experimental designs of future Principal Investigators using these tissues. Results from this study show that the fixative used to preserve a tissue may have an effect on the RIN value, even 
after only one year in storage. Additional tests should be run to compare RNAlater and $\mathrm{LN}_{2}$ preserved tissues across other tissue types and ages.

Work should also be done to examine if there are temporal effects on metabolomics and proteomics data. The Biospecimen Sharing Program aims to provide a variety of tissue samples to researchers. This work could help determine the most appropriate tissue - be it age, fixative, tissue type, etc. - for research proposals. In addition to omics data, these tissues could be useful for other applications such as histopathological studies to determine tissue morphology. Macro and micro structures of tissues could be studied to determine the effects of spaceflight on tissue health, structure, and disease manifestation, among other applications.

\section{DATA AVAILABILITY STATEMENT}

The data analyzed in this report are available through the Ames Life Science Data Archive (https://lsda.jsc.nasa.gov/Experiment) or through the NASA Technical Reports Server (https://www.sti.nasa.gov/).

\section{ACKNOWLEDGEMENTS}

E.D.T. acknowledges support from H.J.S. and the NASA Volunteer Internship Program. We would also like to acknowledge the ALSDA for providing tissue specimens and NASA GeneLab for providing laboratory space.

\section{AUTHOR CONTRIBUTIONS}

H.J.S., K.C., and J.C.R. developed the concept of the experiment. E.D.T. conducted laboratory testing and data analysis while K.C. supervised. V.B. provided laboratory training. V.B., S.H.L.P., and M.T.D. provided laboratory space and equipment. S.H.L.P. and V.B. provided data for CBTM-3, RR1, and RR3 liver sample RNA extractions. A.J.F. and D.K.L. gathered tissues from the ALSDA biobank and provided records of dissection protocols. K.C., J.C.R., and E.D.T. contributed to the discussion of temporal effects on tissue integrity.

\section{ADDITIONAL INFORMATION}

Competing interests: The authors declare no competing interests.

\section{REFERENCES}

Fleige S, Pfaffl M (2006) RNA integrity and the effect on the real-time qRT-PCR performance. Molecular Aspects of Medicine 27: $126-139$

Fleige S, Walf V, Huch S, Prgomet C, Sehm J, Pfaffl M (2006) Comparison of relative mRNA quantification models and the impact of RNA integrity in quantitative real-time RT-PCR. Biotechnology Letters 28: 16011613

Gallego Romero I, Pai A, Tung J, Gilad Y (2014) Impact of RNA degradation on measurements of gene expression. Biomedical Central Biology 12: 42

Ibberson D, Benes V, Muckenthaler M, Castoldi M (2009) RNA degradation compromises the reliability of microRNA expression profiling. Biomedical Central Biotechnology 9: 102

Imbeaud S, Graudens e, Boulanger V, Barlet X, Zaborski P, Eveno E, Mueller O, Schroeder A, Auffray C (2005) Towards standardization of RNA quality assessment using user-independent classifiers of microcapillary electrophoresis traces. Nucleic Acids Research 33: e56

Koppelkamm A, Vennemann B, Lutz-Bonengel S, Fracasso T, Vennemann M (2011) RNA integrity in post-mortem samples: influencing parameters and implications on RT-qPCR assays. International Journal of Legal Medicine 125: 573-580

Lee J K, Williams P D, Cheon S (2008) Data mining in genomics. Clinics in Laboratory Medicine 28: $145-166$

Salazar M, Fernando L, Baig F, Harcum S (2013) The effects of protein solubility on the RNA integrity number (RIN) for recombinant Escherichia coli. Biochemical Engineering Journal 79: 129-135

Schroeder A, Mueller O, Stocker S, Salowsky R, Leiber M, Gassmann M, Lightfoot S, Menzel W, Granzow M, Ragg T (2006) The RIN: an RNA integrity number for assigning integrity values to RNA measurements. Biomedical Central Molecular Biology 7: 3

Sigurgeirsson B, Emanuelsson O, Lundeberg J (2014) Sequencing degraded RNA addressed by 3' tag counting. PLOS ONE 9: e91851 
Talburt et al. -- Temporal RNA Integrity Analysis

Wang H, Owens J, Shih J, Li M, Bonner R, Mushinski J (2006) Histological staining methods preparatory to laser capture microdissection significantly affect the integrity of the cellular RNA. $B M C$ Genomics 7: 97

Wang L, Nie J, Sicotte H, Li Y, Eckel-Passow J, Dasari S, Vedell P, Barman P, Wang L,
Weinshiboum R, Jen J, Huang H, Kohli M, Kocher J (2016) Measure transcript integrity using RNA-seq data. Biomedical Central Bioinformatics 17: 58

Zeng W, Mortazavi A (2012) Technical considerations for functional sequencing assays. Nature Immunology 13: 802-807 